\title{
Free tissue transfer for skull base reconstruction - a review
}

\author{
Brian Swendseid, Mark Chaskes, Ramez Philips, Yamil Selman, Blair Barton, Howard Krein, Ryan \\ Heffelfinger, Adam Luginbuhl, Joseph Curry \\ Department of Otolaryngology-Head and Neck Surgery, Thomas Jefferson University Hospitals, Philadelphia, PA 19107, USA.
}

Correspondence to: Dr. Brian Swendseid, Department of Otolaryngology-Head and Neck Surgery, Thomas Jefferson University Hospitals, 925 Chestnut St, 6th Fl, Philadelphia, PA 19107, USA. E-mail: brianswendseid@gmail.com

\begin{abstract}
How to cite this article: Swendseid B, Chaskes M, Philips R, Selman Y, Barton B, Krein H, Heffelfinger R, Luginbuhl A, Curry J. Free tissue transfer for skull base reconstruction - a review. Plast Aesthet Res 2021;8:41. https://dx.doi.org/10.20517/23479264.2021.47
\end{abstract}

Received: 19 May 2021 First Decision: 15 Jun 2021 Revised: 26 Jun 2021 Accepted: 1 Jul 2021 First online: 12 Jul 2021

Academic Editors: Matthew Spector, Mark K. Wax Copy Editor: Xi-Jun Chen Production Editor: Xi-Jun Chen

\begin{abstract}
Evolutions in skull base surgery and reconstructive technique have given surgeons the confidence to resect and repair increasingly advanced skull base pathologies. Free tissue transfer (FTT) provides a versatile option capable of addressing numerous simultaneous reconstructive goals. This review highlights some of the nuances, challenges, and considerations of performing FTT for skull base reconstruction in the anterior, central and lateral skull base. This review combines the expert opinion of the senior authors with those of the field at large as queried through PubMed searches regarding skull base reconstruction and FTT. Reconstructive goals include separation of intracranial from extracranial cavities, obliteration of dead space, and protection of vascular and neural structures. Atypical vascular pedicle management is commonly needed, especially for endonasal and central skull base resection. Virtual surgical planning may be beneficial for complex bony reconstruction. Familiarity with common complications such as cerebrospinal fluid leak, nasocutaneous fistula, and inferior flap displacement, as well as associations for their development, can help plan the reconstruction to minimize morbidity.
\end{abstract}

Keywords: Skull base, reconstruction, free flap

\section{INTRODUCTION}

Decision-making surrounding the malignant and benign pathology of the skull base remains exceptionally 
challenging. The range of available treatment options, from primary chemotherapy with radiation to multispecialty radical open surgery, all risk significant patient morbidity is given the critical importance of the adjacent central nervous system (CNS) structures, leaving little room for error. When surgical approaches are selected, the reconstructive team must work to convert the complex 3-dimensional defect into a safe, functional, and cosmetically acceptable wound. Thankfully, there has been significant recent growth in the knowledge regarding successful skull base reconstruction, with the expanded use of free tissue transfer (FTT) leading to improvements in patient outcomes. This review highlights some of the considerations and challenges of using FTT in skull base reconstruction.

\section{PRINCIPLES OF SKULL BASE RECONSTRUCTION}

The reconstructive surgeon faces many daunting decisions with serious consequences following extirpative surgery for advanced skull base pathology. Accessing the tumor may mean violating the bony partitions that normally separate the CNS from extracranial spaces, including the nasal, orbital, and oral cavities, and dura and/or brain tissue may be resected. These approaches, therefore, create avenues by which bacteria and air can spread into the normally protected CNS, leading to meningitis, brain abscess, or pneumocephalus ${ }^{[1,2]}$. Thus, a critically important concept for preventing cerebrovascular complications is reestablishing the separation of the intracranial and extracranial cavities. Additionally, when dura has been resected or violated, providing a water-tight dural closure is critical to minimize the risk of cerebrospinal fluid (CSF) $\operatorname{leak}^{[3,4]}$. Non-vascularized grafting is often sufficient, although vascularized tissue can also be inset into the dural repair and integrates well ${ }^{[5]}[$ Figure 1].

Many options exist for reestablishing CNS separation, including local flaps, regional flaps, and FTT. Having a diverse array of tools allows the surgeon to best select the optimal reconstructive for a given patient and defect. Before the rise in popularity of FTT, regional flaps such as the temporoparietal fascia flap (TPFF) and the pericranial flap were commonly employed. With the increasing availability of microvascular expertise, many centers now consider FTT for many of these patients. Head-to-head comparisons have shown improved wound healing and prevention of intracranial complications with FTT compared to regional flaps. This may be due in part to the distal portion of the regional flaps having the most precarious blood supply, which is often also by necessity placed at the most critical portion of the reconstruction ${ }^{[4]}$.

Additional important principles include obliteration of dead space to prevent seroma and hematoma formation, which can become infected and spread intracranially. Any exposed major vessels, such as the carotid artery should be covered with healthy tissue to prevent hemorrhage and blowout. When possible, resected soft tissue and bony structures, should be reconstructed in a way that preserves functionality and is cosmetically acceptable ${ }^{[3,4]}$.

Skull base reconstruction with FTT often requires atypical or creative management of the vascular pedicle. The long distance between the inset site and the cervical vessels that are traditional recipients for anastomosis in head and neck FTT can be addressed with various strategies. One is selecting free flaps such as the radial forearm or fibula free flap, which have long vascular pedicles often capable of reaching the neck. Another is using venous and/or arterial grafting when the pedicle length is insufficient to reach the cervical vessels. However, grafting may be associated with higher failure rates ${ }^{[6,7]}$. Alternative recipient vessels can be used with demonstrated success. For example, the superficial temporal vessels are often easily reachable and have high success rates when there is minimal size mismatch. Unfortunately, prior surgeries such as craniotomies may damage them, making them non-viable recipient vessels ${ }^{[8]}$. The angular vessels are another recipient vessel option that has a high success rate and does not require as long a pedicle as cervical vessels $^{[9]}$. The distal facial vessels can also be accessed with a separate incision near the facial notch of the 


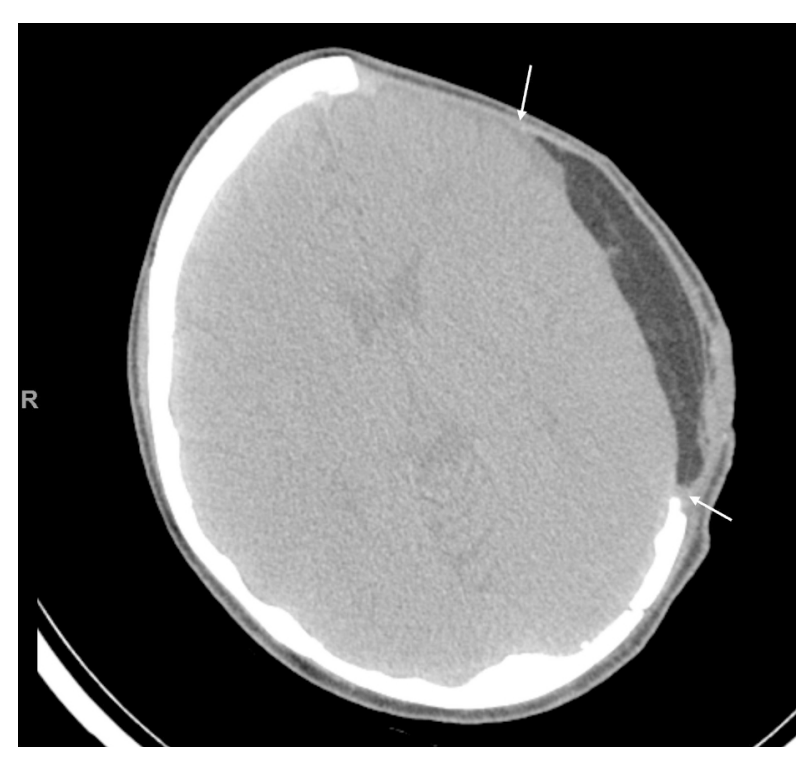

Figure 1. Patient requiring large dural repair for cerebrospinal fluid leak secondary to trauma. Adipofascial anterolateral thigh free flap was selected, with fascial layer sutured directly to dural layer. Post-operative scan at 8 months shows complete integration of the free flap fascia with the dura (arrows).

mandible. These challenges are often magnified if osseous reconstruction is selected, and it is useful to have a plan for recipient vessels and backup prior to incision. In exceptionally complicated bony midfacial and skull base reconstruction in a vessel depleted neck, a second flow through free flap may be an option to bridge the distance from the defect to adequate target vessels ${ }^{[10]}$.

Complex bony reconstruction of the orbital rims, midface, and calvarium may be aided by virtual surgical planning (VSP). VSP shifts some of the mental challenges from the operative setting, where time is critical once under ischemia, to a lower-stress preoperative planning session. In midfacial and periorbital bony reconstruction using parascapular system free flaps (SFF), VSP was associated with more complex bony reconstructions, as well as higher accuracy as measured by the percentage of physical contact between the free flap bone segments. While VSP has not definitely been shown to decrease surgical complications, it allows reconstructive surgeons to perform more complex surgeries with shorter operative and ischemia times $^{[11]}$. VSP can also be used in the setting of secondary revision of prior reconstruction, where the mirror image capabilities allow the overlay of bony projections from the normal side onto the reconstructed side. This shows where flap bone should be removed or repositioned to achieve better bony symmetry.

Consideration of prior therapies is important, as many patients are treated initially with non-surgical or minimally invasive approaches. Patients who have undergone prior radiation or prior surgery are at higher risk for poor wound healing and resultant complications. Local and regional flaps may be less desirable in these circumstances as the flap tissue may exhibit damaged microvasculature from prior radiation or have been devascularized by prior surgery ${ }^{[1,5]}$. Expected adjuvant therapies must also be taken into consideration, as local and regional flaps may be less able to withstand the contracture from radiation, leading lead to fistula and CSF leaks ${ }^{[5]}$. Intraoperative brachytherapy is an option in some recurrent cases that allows targeted dosing to the tumor bed while minimizing radiation effect on adjacent critical structures ${ }^{[2]}$.

\section{Anterior skull base}

Defects of the anterior skull base (ASB) are among the most complicated to reconstruct, as this location represents the intersection of the orbit, nasal cavity, sinuses, pharynx, and dura in a cosmetically important 
area. Orbital exenteration, resection of the orbital roof, floor, rims, and violation of the paranasal sinuses are common. Exenteration results in dural exposure in $20 \%-30 \%$ of cases and CSF leak in up to $16 \%$ of cases ${ }^{[13]}$. Small ASB defects can often be closed with local flaps such as a pericranial or TPFF. Larger defects may require either bony or soft tissue flaps based on the reconstructive goals. The traditional skull base workhorse free flap, rectus abdominus, has largely fallen out of favor and is often replaced in the algorithm with a radial forearm (RFFF) or anterolateral thigh (ALTFF) flap ${ }^{[14-18]}$.

Orbital exenteration cavities with intact periorbital bone can be reconstructed with soft tissue-free flaps. A thinner flap such as an RFFF maintains the concavity of the orbital cavity, facilitating the postoperative use of an orbital implant. However, these thinner flaps may be more susceptible to radiation contracture and the development of orbitocutaneous fistula ${ }^{[19]}$. Bulkier flaps such as an ALTFF or a parascapular system flap with serratus or latissimus muscle (SFF) can be used to slightly overfill the exenteration cavity to account for some expected contracture and can provide some additional support to the skull base closure [Figure 2]. A skin paddle can be used externally for immediate closure of the wound; however, using a muscle flap without a skin paddle produces a superior skin match after re-epithelialization.

For patients who are candidates for orbital preservation, it is common to retain orbital function ( $98 \%$ in one series), although some degree of impairment such as ectropion is common ( $40 \%$ of patients), particularly when adjuvant radiation is employed. Therefore, revision surgery is often required for the management of orbital sequelae in this setting. However, it is rare for a delayed exenteration to be required unless tumor recurrence occurs ${ }^{[20]}$.

Careful attention to the paranasal sinuses can prevent future complications. Exenteration, maxillectomy, and anterior skull base resection will expose the paranasal sinus contents to the surgical site, skull base, and extradural spaces. Reconstruction should aim to re-establish the separation between the contaminated paranasal sinuses and the rest of the wound. Figure 3 demonstrates the many potential pitfalls in free flap reconstruction of these defects. High volume flaps can obstruct natural sinus drainage, such as the frontal outflow tract. As such, when the frontal sinus is violated, care must be taken to remove all sinus mucosa to prevent mucocele formation. Patients are undergoing radiation experience sinus inflammation and deficiencies in mucociliary clearance ${ }^{[21]}$. One should consider performing sinus surgery in the primary or secondary setting for these patients, which helps assist in monitoring for local recurrence and also prevents the sequela of post-radiation sinusitis. A Rains stent can be placed in the frontal outflow tract to prevent scarring during radiation treatment ${ }^{[22]}$.

Low volume flaps risk nasocutaneous fistulas, which can occur due to numerous factors, including contact with contaminated paranasal sinuses, the effects of gravity, and adjuvant radiation therapy. There is an increasing likelihood of fistula with a greater extent of violation of the nasal and paranasal sinus cavities. Commonly, these occur in the superior and medial portions of the orbit. In a series of mostly ALTFFs, a 9\% fistula rate was seen, and in each fistula case, the medial orbital wall or ethmoid sinuses were involved in the resection. Careful attention to these areas during reconstruction by obliterating dead space and properly securing the flap to remnant bony anatomy may avoid this complication, which often requires a second free flap for correction ${ }^{[19]}$.

With the upsloping nature of the ASB, reconstruction must consider the effect gravity will have on the flap. Simply suturing a large soft tissue flap superiorly could result in dehiscence and CSF leak as gravity exerts downward pressure on the tissue bulk. Instead, small holes may be drilled into the calvarium, which can be used to suspend the flap ${ }^{[2]}$. Alternatively, a bone segment from an osteocutaneous radial forearm or 

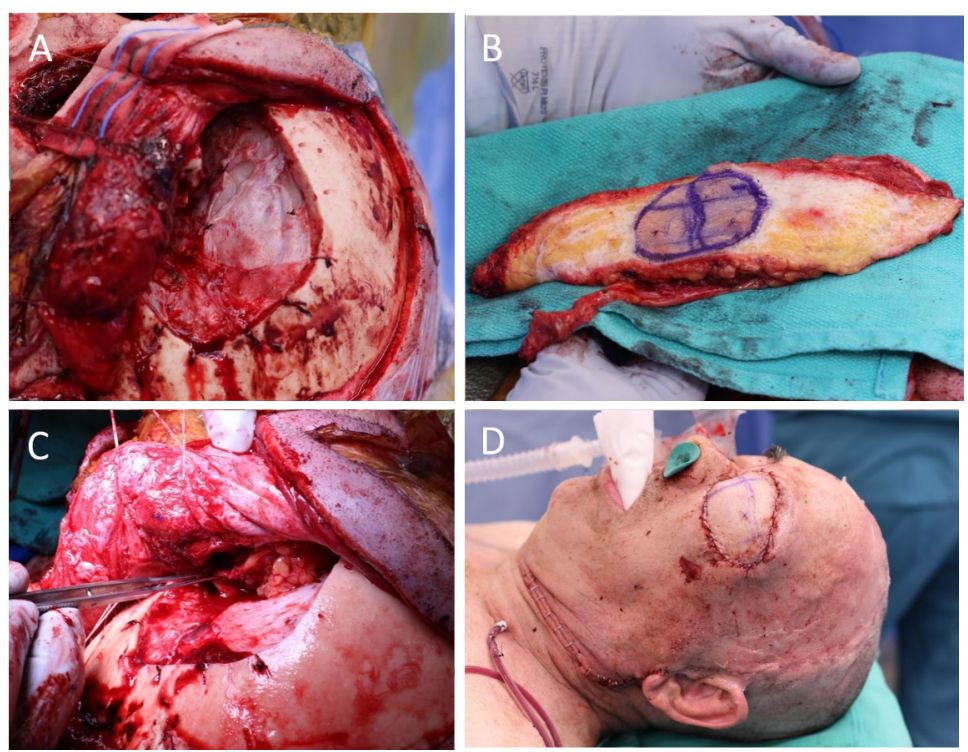

Figure 2. A combined orbital exenteration defect and intracranial resection following dural reconstruction (A). A de-epithelialized anterolateral thigh (B) is chosen to reconstruct the orbit and support the skull base reconstruction. Inset (C) and final appearance (D) are shown.
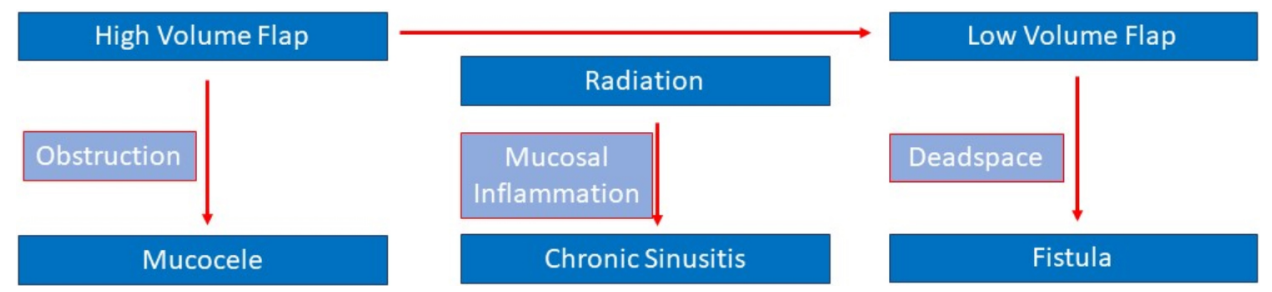

Figure 3. Sinonasal complications in anterior skull base surgery.

parascapular system can be secured to a resected orbital rim space, which provides a framework to maintain the position of the soft tissue, to resist the forces of gravity, and provide some rigid support to the skull base reconstruction $^{[14,23]}[$ Figure 4].

\section{Central skull base}

With the increasing refinement of endonasal approaches to skull base tumors, there has been a shift away from open approaches. This creates significant challenges from a reconstructive standpoint as the access for flap inset and anastomosis is limited. Selecting an endonasal approach to tumor resection of this area has become popular due to the ability to minimize external scarring and brain retraction. However, it requires a comprehensive sinonasal skillset to optimize exposure, visualization, and freedom of motion for one's instruments ${ }^{[24]}$. Commonly employed first options include local tissue flaps such as the nasoseptal flap and turbinate flap, which are often adequate for small to medium-sized defects ${ }^{[25,26]}$. Non-vascularized and synthetic grafts, placed in an onlay or inlay fashion and combined with dural sealant, can often be used for CSF leak closure in central skull base defects with high success rates ${ }^{[27,28]}$. TPFF can be rotated into the nasal cavity for skull base reconstruction by tunneling either through the infratemporal fossa and through the posterior maxillary wall or through a transglabellar keyhole ${ }^{[15]}$. The TPFF can commonly be harvested with at least $12 \mathrm{~cm}$ and is nearly always able to cover the entire clivus or cribriform plate ${ }^{[29]}$. A pericranial flap is another robust option that can be harvested endoscopically and tunneled through a glabellar incision to 

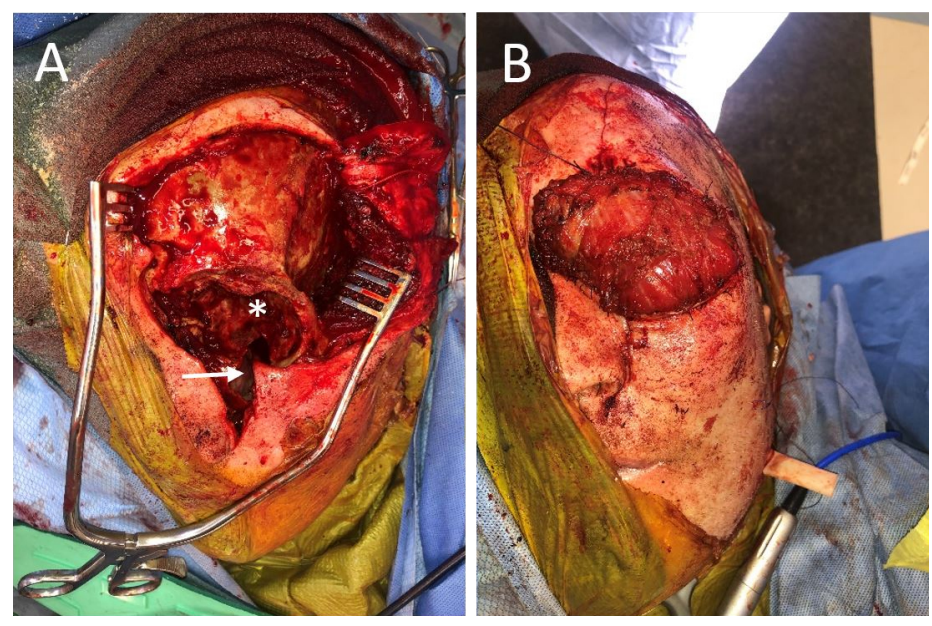

Figure 4. Resection of orbital squamous cell carcinoma resulted in exenteration defect with the removal of the bony orbital apex $\left(^{\star}\right)$ and communication with maxillary sinus (arrow) (A). Parascapular free flap was used with latissimus muscle filling cavity and suspended from scapular tip bone secured to the remnant superior orbital rim (B).

reach the anterior cranial fossa, sella, or clivus ${ }^{[28]}$.

Large defects, particularly those following nasopharyngectomy or clival resection in previously radiated fields, can benefit from FTT. Thinner soft tissue flaps such as the RFFF and ALTFF are excellent options, and muscle-only flaps such as the vastus lateralis flap can be used endonasally as well ${ }^{[30-32]}$. Vastus lateralis flaps have demonstrated efficacy in the salvage setting after CSF leak following local tissue rearrangement for skull base reconstruction ${ }^{[31]}$. Delivery of the flap into the central skull base can be achieved through various approaches. For strictly endonasal resection without neck dissection, a transmaxillary approach may be used. A Caldwell-Luc maxillotomy and medial maxillectomy are performed, and the flap is passed through this defect to the skull base. The pedicle can be passed out with this same defect and anastomosed to the facial or angular system without opening the neck ${ }^{[31,33]}$. When neck dissection is performed, a transcervical inset approach can be used. In this technique, a lateral pharyngotomy is performed at the level of the nasopharynx, often to help deliver the resection specimen, which provides a corridor through which the flap can be passed. The flap can then be anastomosed to traditional cervical vessels such as the facial artery and vein. In either scenario, should the tunnel be too narrow to pass the flap, it may be delivered to the skull base via the mouth and pulled up with endoscopic instruments, with the pedicle passed out the tunnel with a penrose ${ }^{[33]}$.

Endonasal FTT carries a risk of inferior dehiscence and CSF leak. Endonasal sutures and fibrin glue can be used for flap inset ${ }^{[34]}$. In addition, nasal trumpets can be placed to allow bulkier flaps to rest on and provides a nasal airway in the postoperative period. Another technique for preventing inferior flap dehiscence is a retropharyngeal approach to flap inset. In this technique, a tunnel behind the pharynx is bluntly created until the nasopharyngeal defect is reached. The flap can then be passed behind the defect and secured superiorly with sutures and fibrin glue, creating an "underlay" inset rather than an "overlay", in which case gravity pulls the flap into contact with the nasopharyngeal mucosa rather than pulling them apart ${ }^{[33]}$.

\section{Lateral skull base}

Primary temporal bone tumors, parotid malignancy, and skull base pathology may require temporal bone and lateral skull base (LSB) resection. Reconstructive goals for this area include restoration of contour and soft tissue thickness, protection of the great vessels, and epithelial coverage when skin is resection ${ }^{[35]}$. A 
temporoparietal fascia flap is a good option for reconstruction when available but often results in temporal hollowing and alopecia. In the setting of prior radiation, the blood supply may be suboptimal, and infratemporal fossa dissection may inadvertently devascularize the flap ${ }^{[36]}$. Traditionally used rotational options such as the latissimus and trapezius flap often require positioning changes that preclude simultaneous harvest. The submental artery island flap is a good option that can be harvested with mylohyoid and digastric muscle to act as a plug for skull base defects. In a head-to-head comparison to free flaps, submental artery island flaps showed shorter operative time, shorter hospital stays, and lower rates of debulking revision surgery ${ }^{[37]}$. Prior neck dissection may, however, damage the submental pedicle and preclude this option. A pectoralis muscle flap can be harvested with enough length to reach the skull base and is another alternative to FTT in patients who are poor candidates ${ }^{[38]}$.

FTT provides ample bulk for large defects and protection of the great vessels and cranial nerves. Therefore, bony reconstruction is rarely needed, and soft tissue flaps such as ALTFF, RFFF, or rectus free flap can be selected based on the amount of volume restoration needed and the patient's body habitus ${ }^{[39]}$. When skin resection is performed, a free flap with a skin paddle such as an ALTFF can be used. However, the color match is frequently poor. An alternative technique would be raising a cervicofacial advancement flap to cover the skin defect, placed it over a de-epithelialized free flap for contour. This creates an excellent skin color match but maybe suboptimal in active smokers and patients with prior treatment of the neck ${ }^{[39]}$.

Facial nerve resection and rehabilitation are common in LSB resection. Immediate rehabilitation with platinum eyelid weights and tarsal strip procedures are often sufficient for the periorbital region, and cable grafting has good results when viable facial musculature remains. More complex dynamic facial nerve reanimation with masseteric or hypoglossal nerve transfers, crossface grafting, or gracilis FTT should be considered based on the duration of preoperative facial nerve weakness ${ }^{[40]}$. FTT additionally affords the option of harvesting additional neural structures for grafting, such as the nerve to vastus or median antebrachial cutaneous nerve $\mathrm{e}^{[36]}$.

\section{CONCLUSION}

FTT reconstruction of the skull base remains exceptionally challenging given the complexity of the anatomy in such a small area and the unforgiving nature of possible complications. Adherence to principles such as the creation of a watertight seal between intracranial and extracranial cavities, obliteration of dead space, and protection of great vessels and neural structures can minimize complications. Awareness of common complications and antecedent risk factors in their development can aid the surgeon in planning the reconstruction to prevent their development. Continued refinement of techniques for endonasal FTT inset and anastomosis is needed given the advances in endonasal and minimally invasive skull base surgery.

\section{DECLARATIONS}

\section{Authors' contributions}

Conception of work: Swendseid B, Curry J

Writing, editing, final review and accountable for all aspects of work: Swendseid B, Chaskes M, Philips R, Selman Y, Barton B, Krein H, Heffelfinger R, Luginbuhl A, Curry J

\section{Availability of data and materials}

Not applicable. 


\section{Financial support and sponsorship}

None.

\section{Conflicts of interest}

All authors declared that there are no conflicts of interest.

\section{Ethical approval and consent to participate}

Not applicable.

\section{Consent for publication}

Not applicable.

\section{Copyright}

(c) The Author(s) 2021.

\section{REFERENCES}

1. Chepeha DB, Wang SJ, Marentette LJ, Thompson BG, Prince ME, Teknos TN. Radial forearm free tissue transfer reduces complications in salvage skull base surgery. Otolaryngol Head Neck Surg 2004;131:958-63. DOI PubMed

2. Urken ML, Catalano PJ, Sen C, Post K, Futran N, Biller HF. Free tissue transfer for skull base reconstruction analysis of complications and a classification scheme for defining skull base defects. Arch Otolaryngol Head Neck Surg 1993;119:1318-25. DOI PubMed

3. Gullane PJ, Lipa JE, Novak CB, Neligan PC. Reconstruction of skull base defects. Clin Plast Surg 2005;32:391-9, vii. DOI PubMed

4. Neligan PC, Mulholland S, Irish J, et al. Flap selection in cranial base reconstruction. Plast Reconstr Surg 1996;98:1159-66; discussion 1167-8. DOI PubMed

5. Moyer JS, Chepeha DB, Teknos TN. Contemporary skull base reconstruction. Curr Opin Otolaryngol Head Neck Surg 2004;12:294-9. DOI PubMed

6. Maricevich M, Lin LO, Liu J, Chang EI, Hanasono MM. Interposition vein grafting in head and neck free flap reconstruction. Plast Reconstr Surg 2018;142:1025-34. DOI PubMed

7. Cheng HT, Lin FY, Chang SC. Evidence-based analysis of vein graft interposition in head and neck free flap reconstruction. Plast Reconstr Surg 2012;129:853e-4e. DOI PubMed

8. Li J, Shen Y, Wang L, Wang JB, Sun J, Haugen TW. Superficial temporal versus cervical recipient vessels in maxillary and midface free vascularized tissue reconstruction: our 14-year experience. J Oral Maxillofac Surg 2018;76:1786-93. DOI PubMed

9. Hanick A, Ciolek P, Fritz M. Angular vessels for free-tissue transfer in head and neck reconstruction: clinical outcomes. Laryngoscope 2020;130:2589-92. DOI PubMed

10. Di Taranto G, Chen SH, Elia R, et al. Outcomes following head neck free flap reconstruction requiring interposition vein graft or vascular bridge flap. Head Neck 2019;41:2914-20. DOI PubMed

11. Swendseid BP, Roden DF, Vimawala S, et al. Virtual surgical planning in subscapular system free flap reconstruction of midface defects. Oral Oncol 2020;101:104508. DOI PubMed

12. Savard C, Epps G, Ad VB, et al. Cesium-131 interstitial brachytherapy for recurrent malignancies of skull base. J Neurol Surg Rep 2019;80:e23-6. DOI PubMed PMC

13. Limawararut V, Valenzuela AA, Sullivan TJ, et al. Cerebrospinal fluid leaks in orbital and lacrimal surgery. Surv Ophthalmol 2008;53:274-84. DOI PubMed

14. Teknos TN, Smith JC, Day TA, Netterville JL, Burkey BB. Microvascular free tissue transfer in reconstructing skull base defects: lessons learned. Laryngoscope 2002;112:1871-6. DOI PubMed

15. Ein L, Sargi Z, Nicolli EA. Update on anterior skull base reconstruction. Curr Opin Otolaryngol Head Neck Surg 2019;27:426-30. DOI PubMed

16. Bell EB, Cohen ER, Sargi Z, Leibowitz J. Free tissue reconstruction of the anterior skull base: a review. World J Otorhinolaryngol Head Neck Surg 2020;6:132-6. DOI PubMed PMC

17. Ungar OJ, Abergel A, Safadi A, Zaretzki A, Yanko-Arzi R, Fliss DM. Anterior median skull base reconstruction using a vascularized free flap: rationale, patient selection and outcome. J Neurol Surg B Skull Base 2020;81:30-6. DOI PubMed PMC

18. Izquierdo R, Leonetti JP, Origitano TC, al-Mefty O, Anderson DE, Reichman OH. Refinements using free-tissue transfer for complex cranial base reconstruction. Plast Reconstr Surg 1993;92:567-74; discussion 575. PubMed

19. Tassone P, Gill KS, Hsu D, et al. Naso- or orbitocutaneous fistulas after free flap reconstruction of orbital exenteration defects: retrospective study, systematic review, and meta-analysis. J Neurol Surg B Skull Base 2017;78:337-45. DOI PubMed PMC

20. Philips R, Topf MC, Graf A, et al. Orbital outcomes after orbit-sparing surgery and free flap reconstruction. Oral Oncol 2019;98:7884. DOI PubMed

21. Farag A, Rosen MR, Ziegler N, et al. Management and surveillance of frontal sinus violation following craniotomy. $J$ Neurol Surg $B$ Skull Base 2020;81:1-7. DOI PubMed PMC 
22. Parkes WJ, Nyquist GG, Rizzi C, et al. Incidence and management of rhinosinusitis after complex orbitofacial reconstruction. Laryngoscope 2014;124:1059-65. DOI PubMed

23. Vargo JD, Przylecki W, Camarata PJ, Andrews BT. Classification and microvascular flap selection for anterior cranial fossa reconstruction. J Reconstr Microsurg 2018;34:590-600. DOI PubMed

24. Nyquist GG, Rosen MR, Friedel ME, Beahm DD, Farrell CJ, Evans JJ. Comprehensive management of the paranasal sinuses in patients undergoing endoscopic endonasal skull base surgery. World Neurosurg 2014;82:S54-8. DOI PubMed

25. Hachem RA, Elkhatib A, Beer-Furlan A, Prevedello D, Carrau R. Reconstructive techniques in skull base surgery after resection of malignant lesions: a wide array of choices. Curr Opin Otolaryngol Head Neck Surg 2016;24:91-7. DOI PubMed

26. Zuniga MG, Turner JH, Chandra RK. Updates in anterior skull base reconstruction. Curr Opin Otolaryngol Head Neck Surg 2016;24:75-82. DOI PubMed

27. Sigler AC, D'Anza B, Lobo BC, Woodard TD, Recinos PF, Sindwani R. Endoscopic skull base reconstruction: an evolution of materials and methods. Otolaryngol Clin North Am 2017;50:643-53. DOI PubMed

28. Klatt-Cromwell CN, Thorp BD, Del Signore AG, Ebert CS, Ewend MG, Zanation AM. Reconstruction of skull base defects. Otolaryngol Clin North Am 2016;49:107-17. DOI PubMed

29. Siu A, Rangarajan SV, Rabinowitz MR, et al. Quantitative determination of the optimal temporoparietal fascia flap necessary to repair skull-base defects. Int Forum Allergy Rhinol 2020;10:1249-54. DOI PubMed

30. Hanasono MM. Reconstruction after open surgery for skull-base malignancies. J Neurooncol 2020;150:469-75. DOI PubMed

31. Kang SY, Eskander A, Hachem RA, et al. Salvage skull base reconstruction in the endoscopic era: vastus lateralis free tissue transfer. Head Neck 2018;40:E45-52. DOI PubMed

32. Chana JS, Chen HC, Sharma R, Hao SP, Tsai FC. Use of the free vastus lateralis flap in skull base reconstruction. Plast Reconstr Surg 2003;111:568-74; discussion 575. DOI PubMed

33. Sagheer SH, Swendseid B, Evans J, et al. Free tissue transfer for central skull base defect reconstruction: case series and surgical technique. Oral Oncol 2021;115:105220. DOI PubMed

34. Rodriguez-Lorenzo A, Driessen C, Mani M, Lidian A, Gudjonsson O, Stigare E. Endoscopic assisted insetting of free flaps in anterior skull base reconstruction: A preliminary report of five cases. Microsurgery 2020;40:460-7. DOI PubMed

35. O'Connell DA, Teng MS, Mendez E, Futran ND. Microvascular free tissue transfer in the reconstruction of scalp and lateral temporal bone defects. J Craniofac Surg 2011;22:801-4. DOI PubMed

36. Richmon JD, Yarlagadda BB, Wax MK, Patel U, Diaz J, Lin DT. Locoregional and free flap reconstruction of the lateral skull base. Head Neck 2015;37:1387-91. DOI PubMed

37. Howard BE, Nagel TH, Barrs DM, Donald CB, Hayden RE. Reconstruction of lateral skull base defects: a comparison of the submental flap to free and regional flaps. Otolaryngol Head Neck Surg 2016;154:1014-8. DOI PubMed

38. Patel NS, Modest MC, Brobst TD, et al. Surgical management of lateral skull base defects. Laryngoscope 2016;126:1911-7. DOI PubMed

39. Rosenthal EL, King T, McGrew BM, Carroll W, Magnuson JS, Wax MK. Evolution of a paradigm for free tissue transfer reconstruction of lateral temporal bone defects. Head Neck 2008;30:589-94. DOI PubMed

40. Crawford KL, Stramiello JA, Orosco RK, Greene JJ. Advances in facial nerve management in the head and neck cancer patient. Curr Opin Otolaryngol Head Neck Surg 2020;28:235-40. DOI PubMed 